\title{
FENOLOGIA, EXIGÊNCIA TÉRMICA E PRODUTIVIDADE DE VIDEIRAS 'NIAGARA BRANCA', 'NIAGARA ROSADA' E 'CONCORD' SUBMETIDAS A DUAS SAFRAS POR CICLO VEGETATIVO ${ }^{1}$
}

\author{
RAFAEL ANZANELLO ${ }^{2}$, PAULO VITOR DUTRA DE SOUZA ${ }^{3}$, PEDRO FERREIRA COELHO ${ }^{4}$
}

RESUMO - Este trabalho objetivou avaliar a fenologia, a demanda térmica e a produtividade das cvs. Niagara Branca, Niagara Rosada e Concord submetidas a uma poda seca no inverno e a uma poda verde no final da primavera, visando à obtenção de duas safras de uva por ciclo vegetativo. $\mathrm{O}$ experimento foi conduzido em vinhedo pertencente à Estação Experimental Agronômica de Eldorado do Sul-RS, na safra de 2007/2008. As plantas foram submetidas a duas épocas de poda de inverno (22-07-07 e 20-08-07), em cordão esporonado, e duas épocas de poda verde (15-11-07 e 17-12-07), mediante desponte do sarmento a partir da quarta gema acima do último cacho. Os subperíodos fenológicos considerados da videira foram: vegetativo, compreendendo da poda à brotação e da brotação à floração; e reprodutivo, abrangendo da floração à colheita. Os respectivos intervalos tiveram um acompanhamento com base no acúmulo de graus-dia. A produção por planta, sólidos solúveis totais e acidez total titulável foram avaliados em ambas as safras. As cultivares necessitaram aproximadamente de 1.500 graus-dia para completar seu ciclo, tanto na primeira como na segunda safra. A poda de inverno antecipada aumentou a duração do ciclo fenológico das plantas comparativamente à poda de agosto, devido ao aumento do subperíodo poda/floração nas videiras podadas precocemente. A antecipação da poda de inverno antecipou a colheita da primeira safra, possibilitando obter uvas precoces com maior valorização de mercado. A duração do ciclo fenológico da segunda safra foi menor se comparada à primeira safra, devido às temperaturas mais elevadas decorridas no desenvolvimento das plantas submetidas à poda verde. A produtividade da segunda safra foi maior quando a poda seca foi realizada em agosto, associada à poda verde em novembro. Nas plantas submetidas à poda verde, obteve-se uma segunda colheita em meados de março/abril, oferecendo vantagens econômicas ao viticultor e ampliando a disponibilidade da fruta ao consumidor.

Termos de indexação: manejo da poda, soma-térmica, épocas de colheita, Vitis labrusca.

\section{THERMAL REQUIREMENT, PHENOLOGY AND PRODUCTIVITY OF NIAGARA BRANCA, NIAGARA ROSADA AND CONCORD CULTIVARS SUBMITTED TO TWO HARVESTS BY VEGETATIVE CICLE}

\begin{abstract}
This study aimed at tracking phenology, thermal demand and productivity of Niagara Branca, Niagara Rosada and Concord grapevines subjected to a dry pruning in winter and a green pruning in the end of spring, focused on obtaining two grapes harvests by vegetative cycle. The experiment was performed at Eldorado do Sul's Agronomic Experimental Station, Rio Grande do Sul State, Brazil, during the 2007/2008 harvesting. The plants were subjected to two dates of pruning in winter $(07 / 22 / 07$ and $08 / 20 / 07)$, performed by means of a short pruning, and two green pruning dates (11/15/07 and 12/17/07), performed by pruning the shoot starting from the fourth bud above the last grape cluster. The grapevine phenological sub periods considered were the vegetative, ranging from the pruning to sprouting and from the sprouting to flowering; and the reproductive, ranging from flowering to harvesting. Such ranges were monitored based on the degree-day accumulation. The grapevine production, total soluble solids and total titratable acidity were evaluated for the two crops. Results showed that all cultivars need around 1500 degree-days to complete their cycle, for both harvests. Early winter pruning increased the duration of the phenological cycle of plants compared to pruning performed in August due to the increased phenological subperiod pruning/flowering on the grapevines with early pruning. The anticipation of the winter pruning allowed advancing the first harvest, producing early grapes with higher market value. The phenological cycle of the second harvest was shorter than the first harvest due to higher temperatures during development of plants on the green pruning. The combination between winter pruning in August and green pruning in November was the most effective to obtain a second harvest in the same grapevine vegetative cycle. Plants subjected to green pruning provided a second harvest, between March/April, offering economic benefits to the producer and expanding the availability of fruit to consumers.
\end{abstract}

Index terms: pruning management, sum-thermal, harvest period, Vitis labrusca.

\footnotetext{
1(Trabalho 247-11). Recebido em: 10-10-2011. Aceito para publicação em: 10-05-2012.

${ }^{2}$ Eng. Agr., MSc., Pesquisador da FEPAGRO Serra e Doutorando do PPGFitotecnia, UFRGS. Porto Alegre-RS. E-mail: rafael-anzanello@fepagro.rs.gov.br

${ }^{3}$ Eng. Agr., Dr. Prof. Associado, Depto. de Horticultura e Silvicultura, UFRGS. Porto Alegre-RS. Bolsista CNPq. E-mail: pvdsouza@ufrgs.br ${ }^{4}$ Eng. Agr., Depto de Horticultura e Silvicultura, UFRGS. Porto Alegre-RS. E-mail: pedrofcoelho@gmail.com
} 


\section{INTRODUÇÃO}

No Brasil, a viticultura encontra-se entre o paralelo $30^{\circ} \mathrm{S}$, no Estado do Rio Grande do Sul, e o paralelo $9^{\circ} \mathrm{S}$, na região Nordeste do País, englobando diferentes climas e potencialidades de cultivo (GIOVANINNI, 2008).

Em regiões de clima tropical, é tradicional a obtenção de duas ou mais safras de uvas por ano (FOCHESATO et al., 2007). Porém, em regiões de clima subtropical, como no Rio Grande do Sul e Santa Catarina, a videira permite uma única colheita ao ano, sendo que, no caso das cultivares Niagara Branca, Niagara Rosada e Concord, esta se concentra entre a segunda quinzena de janeiro e a primeira quinzena de fevereiro, ocorrendo redução de preço do produto neste período pela alta oferta no mercado (GIOVANINNI, 2008).

Para modificar esse panorama, há práticas culturais que podem alterar a época de colheita. Dentre elas, pode-se lançar mão de um manejo especial com a poda na videira. Esse manejo consiste na execução de uma poda seca no inverno associada a uma poda verde no final da primavera, as quais, dependendo de suas épocas de realização, permitem obter colheitas precoces e/ou tardias mediante duas safras de uva por ciclo vegetativo (ANZANELLO et al., 2008). Porém, esse manejo somente é possível em regiões que não apresentam geadas tardias e que tenham temperaturas e insolação elevadas até meados de abril, sendo que a região da Depressão Central do Rio Grande do Sul se enquadra nessas características.

Segundo Fochesato et al. (2007), o sucesso produtivo da segunda safra está atrelado à combinação entre épocas específicas de poda de inverno e de poda verde. Souza e Fochesato (2007) afirmam que a poda verde, se realizada precocemente, leva a uma pequena produção, devido à insuficiente diferenciação de gemas. E, se executada tardiamente, pode não atingir o ponto de maturação ideal em virtude de a mesma ocorrer no outono, época de baixas temperaturas e insolação.

Tal alternativa de manejo alteraria o perfil da viticultura de mesa no Rio Grande do Sul, provocando mudanças na estrutura de oferta e, consequentemente, do mercado interno deste produto, oferecendo vantagens econômicas ao viticultor, e de disponibilidade da fruta ao consumidor, configurando um cenário mercadológico distinto do apresentado atualmente no Estado.

O conhecimento da fenologia é relevante para os estudos de ampliação do período de safra (JUBILEU et al., 2010). As exigências térmicas e a avaliação do tempo de duração entre diferentes fases fenológicas da cultura permitem a identificação do ciclo das plantas que apresentam frutos com maturação precoce ou tardia (FERREIRA et al., 2004; SATO et al., 2008).

A caracterização fenológica e a quantificação das unidades térmicas necessárias para a videira variam conforme o genótipo e os dados climáticos de cada região (LEÃO; SILVA, 2003). Estudos envolvendo a relação entre o comprimento do ciclo e a temperatura do ar mostram que, em regiões onde a temperatura é mais elevada, o ciclo da cultura é menor, em razão de seu crescimento acelerado (NEIS et al., 2010). A quantidade de energia necessária para a videira completar seu ciclo geralmente é expressa em graus-dia, que é a diferença acumulada entre a temperatura média e a temperatura-base abaixo da qual a planta não se desenvolve (SOUZA et al., 2009). Segundo Santos et al. (2007), a temperatura basal da videira é de $10^{\circ} \mathrm{C}$.

O objetivo deste trabalho foi descrever a fenologia, estimar a necessidade térmica e avaliar a produtividade das videiras 'Niagara Branca', 'Niagara Rosada' e 'Concord' submetidas a uma poda seca no inverno e uma poda verde no final da primavera, visando à obtenção de duas safras de uva por ciclo vegetativo na região edafoclimática da Depressão Central do Rio Grande do Sul.

\section{MATERIAL E MÉTODOS}

O experimento foi conduzido na Estação Experimental Agronômica da UFRGS (30 $00^{\circ}$ '27'S; $51^{\circ} 40^{\prime} 18^{\prime \prime} \mathrm{W}$; altitude de $46 \mathrm{~m}$ ), localizada no município de Eldorado do Sul - RS, na região da Depressão Central do Rio Grande do Sul. O solo do local é classificado como Argissolo Vermelho distrófico de textura argilosa e relevo ondulado, tendo como substrato o granito. Normalmente, são solos bem drenados, fortemente ácidos, com saturação e soma de bases baixa e com teores baixos de matéria orgânica. Segundo Köeppen, o clima da região é classificado como Cfa. A precipitação pluviométrica anual média é de $1.446 \mathrm{~mm}$, e a umidade relativa do ar anual média é $77 \%$. A radiação solar global média é de $12,39 \mathrm{MJ} \mathrm{m}^{-2} \mathrm{dia}^{-1}$. O número médio de horas de frio com temperaturas inferiores a $7,2^{\circ} \mathrm{C}$ é de 213 horas de maio a agosto (BERGAMASCHI et al., 2003).

Para o experimento, utilizou-se de três cultivares de videira Niagara Branca, Niagara Rosada e Concord, enxertadas sobre o porta-enxerto 101-14 mgt, com 16 anos de idade. As plantas encontravamse espaçadas por $1,20 \mathrm{~m}$ dentro da fila e $3 \mathrm{~m}$ entre filas, sustentadas pelo sistema de condução tipo espaldeira, com 3 fios de arame, a $95 \mathrm{~cm}$ do solo, e 
espaçados $55 \mathrm{~cm}$ cada.

O delineamento experimental utilizado foi o completamente casualizado, com oito repetições e uma planta por parcela, sendo testadas duas épocas de poda de inverno (20-07-2007, 22-08-2007) e duas épocas de poda verde (15-11-2007, 17-12-2007). Os tratamentos consistiram em: Testemunha 1 - Poda de inverno em 20-07-2007 - sem poda verde; Testemunha 2 - Poda de inverno em 22-08-2007 - sem poda verde; T1 - Poda de inverno em 20-07-2007 e poda verde em 15-11-2007; T2 - Poda de inverno em 2007-2007 e poda verde em 17-12-2007; T3 - Poda de inverno em 22-08-2007 e poda verde em 15-11-2007; T4 - Poda de inverno em 22-08-2007 e poda verde em 17-12-2007.

A poda de inverno consistiu em deixar-se duas a três gemas por ramo, em cordão esporonado, com aproximadamente 20 gemas por planta. Todas as plantas foram submetidas à superação de dormência mediante pulverização de cianamida hidrogenada a $2 \%$, imediatamente após a poda seca. A poda verde foi feita mediante o desponte do sarmento a partir da quarta gema acima do último cacho e a eliminação das feminelas ou netos, forçando a brotação das gemas francas. As plantas-testemunha somente receberam desponte do sarmento acima do $3^{\circ}$ fio de arame, o que correspondeu a mais de oito folhas acima do último cacho.

Durante o período experimental, a fenologia das cultivares Niagara Branca, Niagara Rosada e Concord foi acompanhada semanalmente, ao longo dos tratamentos, baseada na escala de Eichorn e Lorenz, segundo European and Mediterranean Plant Protection Organization (1984). Os estádios fenológicos e sua caracterização foram: brotação, quando $50 \%$ das gemas de todas as plantas se apresentavam no estádio de ponta verde; floração, quando todas as plantas apresentavam 50\% dos cachos com algumas flores abertas; colheita, quando todos os cachos de todas as plantas se encontravam colhidos. A colheita, nas duas produções, foi realizada de forma fracionada, sendo em cada repasse colhidos apenas os frutos que se apresentavam em plena maturação tecnológica. $\mathrm{O}$ ponto de colheita foi determinado por avaliações sensoriais da uva (sabor e odor).

Os subperíodos fenológicos considerados para o ciclo vegetativo e reprodutivo das duas safras foram: número de dias da poda à brotação; da brotação à floração, e da floração à colheita. Os respectivos intervalos tiveram um acompanhamento com base no acúmulo de graus-dia segundo a metodologia proposta por Villa Nova et al. (1972), adotando-se a temperatura-base de $10{ }^{\circ} \mathrm{C}$.
$\mathrm{GD}=(\mathrm{Tm}-\mathrm{Tb})+(\mathrm{TM}-\mathrm{Tm}) / 2$, para $\mathrm{Tm}>\mathrm{Tb} ;$

$\mathrm{GD}=(\mathrm{TM}-\mathrm{Tb})^{2} / 2(\mathrm{TM}-\mathrm{Tm})$, para $\mathrm{Tm}<\mathrm{Tb}$; $\mathrm{GD}=0$, para $\mathrm{Tb}>\mathrm{TM}$.

sendo GD = graus-dia; $\mathrm{TM}=$ temperatura máxima diária $\left({ }^{\circ} \mathrm{C}\right) ; \mathrm{Tm}=$ temperatura mínima diária $\left({ }^{\circ} \mathrm{C}\right)$, e $\mathrm{Tb}=$ temperatura-base $\left({ }^{\circ} \mathrm{C}\right)$.

As épocas de colheita das videiras 'Niagara Branca', 'Niagara Rosada' e 'Concord' foram avaliados nas duas safras, relacionando-as com a cotação de preços para a categoria uvas de mesa comum, segundo a CEASA - Porto Alegre-RS, no período compreendido entre 27-12-2007 a 16-04-2008 (CEASA, 2008). A quantidade relativa de frutos colhidos em cada época de colheita também foi considerada.

A produção por planta, sólidos solúveis totais (SST) e acidez total titulável (ATT) foram avaliados para as duas safras. Os cachos colhidos tiveram sua massa anotada, em $\mathrm{kg}$, através da pesagem em balança eletrônica, marca Urano, modelo UDC 30000/5. Para a análise da composição química dos frutos da primeira e segunda safras foram coletados dez e cinco cachos de uva por unidade experimental, respectivamente. $\mathrm{O}$ valor de SST foi determinado em refratômetro de mesa, modelo 2WAJ, a partir de amostra de 20 microlitros de mosto extraído por prensagem manual. Para a determinação da ATT, 6 $\mathrm{g}$ de polpa foram macerados em almofariz, e posteriormente diluídos em $100 \mathrm{~mL}$ de água destilada. Procedeu-se à titulação da amostra sob agitação, com solução de $\mathrm{NaOH} 0,1 \mathrm{~N}$ previamente padronizada com biftalato de potássio. Os resultados foram expressos em $\mathrm{cmol} \mathrm{L}^{-1}$, determinados pela quantidade de solução gasta até atingir pH 8,1 (CALEGARO et al., 2002).

As variáveis de produção quantitativa e qualitativa foram submetidas à análise de variância. Os resultados com diferenças significativas, pelo teste "F", tiveram suas médias submetidas ao teste de Duncan, ao nível de significância de $5 \%$ de probabilidade.

\section{RESULTADOS E DISCUSSÃO}

O ciclo fenológico entre a poda e a colheita das plantas-testemunha podadas em 20-07-07 foi de 160 dias para as cvs. Niagara Branca e Niagara Rosada, e de 167 dias para a 'Concord' (Tabela 1). Por sua vez, o ciclo das plantas submetidas à poda de inverno, em 22-08-07, foi de 147 dias para a 'Niagara Branca' e 'Niagara Rosada', e de 154 para a 'Concord'. Estes ciclos assemelharam-se àqueles observados por Fochesato et al. (2007), que avaliaram as mesmas cultivares e as mesmas épocas de 
poda de inverno nas condições da Depressão Central do Rio Grande do Sul.

Nas videiras submetidas à poda verde, verificou-se o aumento do subperíodo floração à colheita, se comparadas às plantas não podadas no final da primavera, para o ciclo de produção da primeira safra (Tabela 1). Esse aumento pode ser explicado pela redução da área fotossintética no ramo devido à execução da poda verde associado a uma alteração temporária da rota dos fotoassimilados, os quais, em ramos não podados, foram translocados preferencialmente aos frutos, enquanto nos podados, parte deve ser sido direcionada para promover as novas brotações.

O aumento na duração do ciclo vegetativo da primeira safra nas plantas podadas em julho, comparada às podadas em agosto, ocorreu, principalmente, em virtude do aumento do subperíodo compreendido entre a poda e a floração (Tabela 1), como consequência das temperaturas mais amenas ocorridas durante esse intervalo (Figura 1). Embora tenha havido maior duração do ciclo nas plantas podadas em julho, a precocidade de execução da poda permitiu antecipação na brotação e, consequentemente, adiantamento na colheita dos frutos. Ferreira et al. (2004) também obtiveram antecipação da colheita trabalhando com a poda em julho, na cultivar Niagara Rosada, no Sul de Minas Gerais, se comparada à poda convencional realizada em agosto.

Nas plantas podadas em 20-07-07, o início da brotação foi antecipado em 25, 28 e 23 dias em relação àquelas podadas em agosto para as cultivares Niagara Branca, Niagara Rosada e Concord, respectivamente. Outros autores também anteciparam a brotação em diferentes cultivares de videiras através da antecipação da poda (MURAKAMI et al., 2002; NEIS et al., 2010). Para Sozim et al. (2007), a antecipação da poda de inverno deve ser feita em condições climáticas em que não haja risco de geadas primaveris. Segundo Mandelli et al. (2003), a poda precoce, associada à aplicação de cianamida hidrogenada, visando a antecipar a brotação na região da Serra Gaúcha, pode causar consideráveis danos à planta e à produção, em virtude de os vinhedos estarem sujeitos a geadas no início do ciclo vegetativo.

O ciclo fenológico das plantas submetidas à segunda safra das podas verdes, em 15-11-07 e 17-12-07, a colheita, foi de 120 dias para a 'Niagara Branca' e 113 dias para a 'Niagara Rosada' (Tabela 1). A cultivar Concord apresentou ciclo cerca de sete dias maior que a 'Niagara Branca' e a 'Niagara Rosada', para ambas as épocas de poda verde (Tabela 1). Conte (1996), trabalhando com a videira 'Niagara Rosada', em ambiente protegido na região da Serra Gaúcha, obteve valor de 126 dias com a execução da poda verde, próximo ao alcançado no presente estudo. Já, Anzanello et al. (2008) obtiveram um ciclo fenológico para a cultivar Niagara Branca de 127 dias para a poda verde realizada em novembro e de 113 para a de dezembro, na região da Depressão Central do Rio Grande do Sul.

O maior ciclo fenológico da cultivar Concord, nas duas safras de uva em relação à 'Niagara Branca' e a 'Niagara Rosada', deveu-se, basicamente, à maior duração entre a poda e a floração, visto que, no subperíodo posterior, o intervalo foi semelhante para todas as cultivares (Tabela 1).

A redução do ciclo compreendido entre a poda verde e a colheita da segunda safra em relação à poda de inverno à colheita da primeira safra foi consequência das temperaturas mais elevadas ocorridas durante o desenvolvimento das plantas submetidas à poda verde (Figura 1). Como a videira é condicionada pela disponibilidade térmica para completar seu ciclo (SANTOS et al., 2007), a temperatura média mais alta nos meses que precederam a segunda colheita foi um dos principais fatores responsáveis pelo encurtamento do seu ciclo de produção.

O acúmulo térmico da poda de inverno à primeira colheita e da poda verde à segunda colheita foi em torno de 1.450 a 1.550 graus-dia para as cultivares Niagara Branca e Niagara Rosada (Tabela 2). No caso da videira 'Concord', houve a necessidade de maior acúmulo térmico, tanto na primeira como para a segunda safra, verificado principalmente pelo aumento da necessidade térmica da brotação à floração. Tal comportamento foi similar ao encontrado por Anzanello et al. (2008), em condições idênticas de trabalho. O início da brotação para todas as cultivares, independentemente da época e do tipo de poda realizada, relacionou-se diretamente com o acúmulotérmico assinalado, havendo uma exigência térmica maior para a videira 'Concord' alcançar a brotação (Tabela 2).

As plantas-testemunha (sem poda verde) das cvs. Niagara Branca e Niagara Rosada, podadas em 20-07-07, tiveram seus frutos colhidos no dia 27-1207 (Tabela 3). Já, as plantas da cv. Concord apresentaram a colheita no dia 03-01-08. Fochesato et al. (2007) afirmam que colheitas às vésperas das festas de fim ano, ocasião em que o mercado se encontra aquecido pela grande procura por uva, oferecem vantagens econômicas aos viticultores. Para as plantas-testemunha podadas em agosto, os frutos foram colhidos no dia 16-01-08 para as cvs. Niagara Branca e Niagara Rosada e no dia 23-01-08 para a 'Concord' (Tabela 3). A antecipação da poda de inverno poderia resultar 
aos produtores ganhos de até $43 \%$ pelo preço do $\mathrm{kg}$ da uva 'Niagara Branca' e 'Niagara Rosada' e de até $71 \%$ para a uva 'Concord', em relação à época de poda seca mais tardia (Tabela 4).

Para as videiras podadas em julho e submetidas à poda verde, houve atraso de até 10 dias para a colheita plena da primeira produção nas cultivares 'Niagara Branca' e 'Niagara Rosada' e de até 13 dias para a 'Concord', se comparadas às plantastestemunha (Tabela 3). Já, para as plantas podadas em agosto e sujeitadas à poda verde, houve um retardamento máximo de 7 dias na colheita total da primeira safra, para todas as cultivares, em relação àquelas somente despontadas. Resultados semelhantes foram obtidos por Souza e Fochesato (2007), na cultivar Niagara Branca, que obtiveram atraso de uma semana na primeira colheita com o emprego da poda verNas plantas dos tratamentos T1 e T2, as colheitas referentes à primeira safra ocorreram em quatro datas: 30-12-07; 06-01-08; 10-01-08 e 16-01-08 (Figura $2 \mathrm{~A})$, em períodos favoráveis à comercialização (Tabela 4). Em relação às plantas dos tratamentos T3 e T4, as colheitas da primeira produção ocorreram em 19-01-08; 23-01-08 e 30-01-08 (Figura 2B), junto ao pico de oferta da fruta no Estado do Rio Grande do Sul (Tabela 4). Já, para a segunda produção, obtiveram-se três colheitas para as plantas podadas em novembro, nas datas de 07-03-08; 15-03-08 e 22-03-08 (Figura $2 \mathrm{C}$ ), e três colheitas para as podadas em dezembro, nos dias 02-04-08; 09-04-08 e 16-04-08 (Figura 2D). Souza e Fochesato (2007) e Anzanello et al. (2008) também obtiveram colheitas entre março e abril com a execução da poda verde, possibilitando ampliar o período de oferta da fruta no mercado para as cultivares Niagara Branca, Niagara Rosada e Concord.

A colheita dos frutos iniciou-se pela 'Niagara Branca' e 'Niagara Rosada' e encerrou-se pela cv. Concord, independentemente da safra e da época de poda (Figura 2). Segundo Mandelli et al. (2003), a 'Niagara Branca' e a 'Niagara Rosada' apresentam ponto de maturação anterior a 'Concord', na região da 'Serra Gaúcha', devido às características genéticas inerentes às cultivares, que condicionam à fenologia da planta.

A produção média por planta na primeira safra não variou entre a 'Niagara Branca' e a 'Niagara Rosada', porém diferiu significativamente para a cultivar Concord, a qual apresentou menor produtividade (Tabela 5). Em relação aos tratamentos de poda, o T3 mostrou leve tendência de queda na produção por planta para todas as cultivares (Tabela 5). Isso provavelmente se deva à maior alteração na rota de fotoassimilados ocorrida no tratamento $\mathrm{T} 3$, em função do maior número de brotações procedentes da poda verde neste tratamento (dados não mostrados), as quais atuavam como drenos aos fotoassimilados destinados ao desenvolvimento e à maturação da primeira produção.

Para a segunda produção, o tratamento T3 promoveu maior produção por planta, indicando a importância da combinação entre as épocas de poda de inverno e poda verde para o sucesso da colheita (Tabela 5). A cultivar Niagara Branca foi a mais propensa para a adoção do manejo estabelecido, proporcionando uma produtividade na segunda safra equivalente a $3.500 \mathrm{~kg} \mathrm{ha}^{-1}$, seguida pela Niagara Rosada, com uma produtividade de $2.333 \mathrm{~kg} \mathrm{ha}^{-1} \mathrm{e}$ $1.333 \mathrm{~kg} \mathrm{ha}^{-1}$ para a Concord. De modo geral, o baixo rendimento das plantas submetidas à poda verde pode estar atrelado ao período de déficit hídrico ocorrido no verão (Figura 1), o qual afetou, além da emissão, o desenvolvimento dos brotos responsáveis pela segunda safra. A utilização da irrigação torna-se ferramenta importante nesse sistema de produção para elevar a produtividade da segunda safra, em regiões do RS sujeitas à falta de chuvas no verão.

Segundo Giovaninni (2008), o rendimento da safra normal para Niagara Branca, Niagara Rosada e Concord, no Estado do Rio Grande do Sul, obtida através da poda seca no inverno, é de 15 a $20 \mathrm{t} \mathrm{ha}^{-1}$. Com a produção oriunda da poda verde, um incremento na produção total anual de uva seria obtido, significando um ganho extra ao viticultor. Vale salientar que os baixos níveis de precipitação evidenciados durante o período vegetativo da segunda safra (Figura 1) demandaram apenas duas aplicações de produtos fitossanitários em relação a 14 aplicações realizadas da poda à colheita da primeira safra. Tais fatos apontam a economicidade favorável à prática de duas podas da videira e duas safras por ano na Depressão Central do Rio Grande do Sul.

Para as condições experimentais do estudo, sugere-se empregar a poda verde para a obtenção de uma segunda safra a cada dois ciclos vegetativos para não debilitar demasiadamente a videira para as safras seguintes, sobretudo em porta-enxertos de baixo vigor, como o utilizado no presente trabalho (101-14). Ghilardi e Maia (2001) relatam que vários ciclos com duas produções de uvas podem reduzir a vida útil do parreiral. Vide experiência com portaenxerto Riparia do Traviú, de baixo vigor, na região de Jundiaí-SP.

Em relação à análise qualitativa dos frutos, verificou-se que os frutos da segunda safra apresentaram menor valor de SST e maior acidez para 'Niagara Branca', 'Niagara Rosada' e 'Concord', se comparados à primeira safra (Tabela 6).

O menor índice de SST dos frutos da segunda 
safra pode explicar-se pelo excesso de chuvas presenciado durante os meses de março e abril, período em que ocorreu o amadurecimento da segunda produção (Figura 1). Segundo Tecchio et al. (2007), altos níveis de precipitação no período de maturação prejudicam a qualidade da uva por impossibilitar concentração satisfatória de açúcares nos frutos, promover podridões e necessitar de colheitas antecipadas. Já, o aumento médio no valor de ATT da segunda colheita, comparado à primeira, possivelmente tenha ocorrido devido à menor degradação dos ácidos orgânicos (POMMER et al., 2003). Segundo Guerra et al. (1992), os ácidos são os compostos preponderantemente consumidos à noite para manutenção do metabolismo da planta. Assim, a maior queda da temperatura à noite, junto à maturação da segunda produção (Figura 1), atribuiu às plantas um menor dispêndio de energia e, consequentemente, um maior acúmulo de ácidos em seus cachos.

As variáveis qualitativas (SST e ATT) diferiram entre as cultivares (Tabela 6). A 'Concord' apresentou maior ATT e menor SST se comparada à 'Niagara Branca' e 'Niagara Rosada', não havendo diferenças entre as últimas. As diferenças apontadas nas características químicas das cultivares estudadas devem-se, provavelmente, às características genéticas inerentes às cultivares (CAMARGO; DIAS, 1984).

TABELA 1 - Duração (dias) entre os subperíodos fenológicos da videira cvs. Niagara Branca (A), Niagara Rosada (B) e Concord (C), submetidas a duas épocas de poda de inverno e de poda verde. Eldorado do Sul-RS.

\begin{tabular}{|c|c|c|c|c|c|c|}
\hline \multirow{3}{*}{ Subperíodos fenológicos } & \multicolumn{6}{|c|}{ Duração (dias) (A) } \\
\hline & \multicolumn{2}{|c|}{$\begin{array}{l}\text { Poda de inverno } \\
\text { (sem poda verde) }\end{array}$} & \multicolumn{2}{|c|}{$\begin{array}{l}\text { Poda de inverno } \\
\text { (com poda verde) }\end{array}$} & \multicolumn{2}{|c|}{ Poda verde } \\
\hline & 20-07-07 & 22-08-07 & 20-07-07 & 22-08-07 & 15-11-07 & 17-12-07 \\
\hline Poda/Brotação & 35 & 27 & 35 & 27 & 15 & 12 \\
\hline Brotação/Floração & 39 & 34 & 39 & 34 & 26 & 24 \\
\hline Floração/Colheita & 86 & 86 & 96 & 93 & 79 & 77 \\
\hline Poda/Colheita & 160 & 147 & 170 & 154 & 120 & 113 \\
\hline \multirow{3}{*}{ Subperíodos fenológicos } & \multicolumn{6}{|c|}{ Duração (dias) (B) } \\
\hline & \multicolumn{2}{|c|}{$\begin{array}{l}\text { Poda de inverno } \\
\text { (sem poda verde) }\end{array}$} & \multicolumn{2}{|c|}{$\begin{array}{l}\text { Poda de inverno } \\
\text { (com poda verde) }\end{array}$} & \multicolumn{2}{|c|}{ Poda verde } \\
\hline & 20-07-07 & 22-08-07 & 20-07-07 & 22-08-07 & 15-11-07 & 17-12-07 \\
\hline Poda/Brotação & 33 & 28 & 33 & 28 & 14 & 12 \\
\hline Brotação/Floração & 38 & 33 & 38 & 33 & 25 & 23 \\
\hline Floração/Colheita & 89 & 86 & 99 & 93 & 81 & 78 \\
\hline Poda/Colheita & 160 & 147 & 170 & 154 & 120 & 113 \\
\hline \multirow{3}{*}{ Subperíodos fenológicos } & \multicolumn{6}{|c|}{ Duração (dias) (C) } \\
\hline & \multicolumn{2}{|c|}{$\begin{array}{c}\text { Poda de inverno } \\
\text { (sem poda verde) }\end{array}$} & \multicolumn{2}{|c|}{$\begin{array}{l}\text { Poda de inverno } \\
\text { (com poda verde) }\end{array}$} & \multicolumn{2}{|c|}{ Poda verde } \\
\hline & 20-07-07 & 22-08-07 & 20-07-07 & 22-08-07 & 15-11-07 & 17-12-07 \\
\hline Poda/Brotação & 39 & 29 & 39 & 29 & 18 & 14 \\
\hline Brotação/Floração & 43 & 38 & 43 & 38 & 29 & 28 \\
\hline Floração/Colheita & 85 & 87 & 98 & 94 & 80 & 78 \\
\hline Poda/Colheita & 167 & 154 & 180 & 161 & 127 & 120 \\
\hline
\end{tabular}


TABELA 2 - Soma de graus-dia $\left({ }^{\circ} \mathrm{C}\right)$ entre os subperíodos fenológicos da videira cvs. Niagara Branca (A), Niagara Rosada (B) e Concord (C), submetidas a duas épocas de poda de inverno e duas épocas de poda verde. Eldorado do Sul-RS.

\begin{tabular}{|c|c|c|c|c|c|c|}
\hline \multirow{3}{*}{$\begin{array}{l}\text { Subperíodos } \\
\text { fenológicos }\end{array}$} & \multicolumn{6}{|c|}{ Soma de graus-dia $\left({ }^{\circ} \mathrm{C}\right)(\mathrm{A})$} \\
\hline & \multicolumn{2}{|c|}{$\begin{array}{l}\text { Poda de inverno } \\
\text { (sem poda verde) }\end{array}$} & \multicolumn{2}{|c|}{$\begin{array}{l}\text { Poda de inverno } \\
\text { (com poda verde) }\end{array}$} & \multicolumn{2}{|c|}{ Poda verde } \\
\hline & 20-07-07 & 22-08-07 & 20-07-07 & 22-08-07 & 15-11-07 & 17-12-07 \\
\hline Poda/Brotação & 162,3 & 202,3 & 162,3 & 202,3 & 147,4 & 156,7 \\
\hline Brotação/Floração & 274,5 & 275,3 & 274,5 & 275,3 & 323,9 & 351,9 \\
\hline Floração/Colheita & 1002,7 & 1021,0 & 1060,1 & 1056,8 & 1056,2 & 973,2 \\
\hline Poda/Colheita & 1439,5 & 1498,6 & 1496,9 & 1534,4 & 1527,5 & 1481,8 \\
\hline \multirow{3}{*}{$\begin{array}{l}\text { Subperíodos } \\
\text { fenológicos }\end{array}$} & \multicolumn{6}{|c|}{ Soma de graus-dia $\left({ }^{\circ} \mathrm{C}\right)(\mathrm{B})$} \\
\hline & \multicolumn{2}{|c|}{$\begin{array}{l}\text { Poda de inverno } \\
\text { (sem poda verde) }\end{array}$} & \multicolumn{2}{|c|}{$\begin{array}{l}\text { Poda de inverno } \\
\text { (com poda verde) }\end{array}$} & \multicolumn{2}{|c|}{ Poda verde } \\
\hline & 20-07-07 & 22-08-07 & 20-07-07 & 22-08-07 & 15-11-07 & 17-12-07 \\
\hline Poda/Brotação & 150,8 & 208,2 & 150,8 & 208,2 & 138,1 & 156,7 \\
\hline Brotação/Floração & 264,1 & 269,4 & 264,1 & 269,4 & 304,1 & 340,6 \\
\hline Floração/Colheita & 1024,6 & 1021,0 & 1082,0 & 1056,8 & 1085,3 & 984,5 \\
\hline Poda/Colheita & 1439,5 & 1498,6 & 1496,9 & 1534,4 & 1527,5 & 1481,8 \\
\hline \multirow{3}{*}{$\begin{array}{l}\text { Subperíodos } \\
\text { fenológicos }\end{array}$} & \multicolumn{6}{|c|}{ Soma de graus-dia $\left({ }^{\circ} \mathrm{C}\right)(\mathrm{C})$} \\
\hline & \multicolumn{2}{|c|}{$\begin{array}{l}\text { Poda de inverno } \\
\text { (sem poda verde) }\end{array}$} & \multicolumn{2}{|c|}{$\begin{array}{l}\text { Poda de inverno } \\
\text { (com poda verde) }\end{array}$} & \multicolumn{2}{|c|}{ Poda verde } \\
\hline & 20-07-07 & 22-08-07 & 20-07-07 & 22-08-07 & 15-11-07 & 17-12-07 \\
\hline Poda/Brotação & 175,4 & 215,1 & 175,4 & 215,1 & 169,3 & 187,3 \\
\hline Brotação/Floração & 341,6 & 314,5 & 341,6 & 314,5 & 363,2 & 378,3 \\
\hline Floração/Colheita & 1043,3 & 1037,3 & 1086,9 & 1092,1 & 1083,8 & 989,8 \\
\hline Poda/Colheita & 1560,3 & 1566,9 & 1603,9 & 1621,7 & 1616,3 & 1554,4 \\
\hline
\end{tabular}

TABELA 3 - Períodos de colheita para as cvs. de videiras Niagara Branca, Niagara Rosada e Concord, submetidas a duas épocas de poda de inverno e duas épocas de poda verde. Eldorado do Sul-RS.

\begin{tabular}{|c|c|c|c|c|c|c|}
\hline \multirow{3}{*}{ Tratamento* } & \multicolumn{6}{|c|}{ Épocas de colheita } \\
\hline & \multicolumn{2}{|c|}{ Niagara Branca } & \multicolumn{2}{|c|}{ Niagara Rosada } & \multicolumn{2}{|c|}{ Concord } \\
\hline & $1^{\text {a }}$ safra & $2^{a}$ safra & $1^{a}$ safra & $2^{a}$ safra & $1^{a}$ safra & $2^{a}$ safra \\
\hline TEST 1 & $27-12-07$ & ------- & $27-12-07$ & ------ & 03-01-07 & ------- \\
\hline TEST 2 & $16-01-08$ & ------- & $16-01-08$ & ------- & 23-01-08 & ------- \\
\hline $\mathrm{T} 1$ & \multirow{2}{*}{$\begin{array}{c}30-12-07 \text { a } \\
06-01-08\end{array}$} & $\begin{array}{c}08-03-08 \text { a } \\
15-03-08\end{array}$ & \multirow{2}{*}{$\begin{array}{c}30-12-07 \\
\mathrm{a} \\
06-01-08\end{array}$} & $\begin{array}{c}08-03-08 \text { a } \\
15-03-08\end{array}$ & \multirow{2}{*}{$\begin{array}{c}06-01-07 \\
a \\
16-01-08\end{array}$} & $\begin{array}{c}15-03-08 \mathrm{a} \\
22-03-08\end{array}$ \\
\hline $\mathrm{T} 2$ & & $\begin{array}{c}02-04-08 \text { a } \\
09-04-08\end{array}$ & & $\begin{array}{c}02-04-08 \text { a } \\
09-04-08\end{array}$ & & $\begin{array}{c}09-04-08 \text { a } \\
16-04-08\end{array}$ \\
\hline $\mathrm{T} 3$ & $19-01-08 \mathrm{a}$ & $\begin{array}{c}08-03-08 \text { a } \\
15-03-08\end{array}$ & \multirow{2}{*}{$\begin{array}{c}19-01-08 \mathrm{a} \\
23-01-08\end{array}$} & $\begin{array}{c}08-03-08 \text { a } \\
15-03-08\end{array}$ & \multirow{2}{*}{$\begin{array}{c}23-01-08 \\
a \\
30-01-08\end{array}$} & $\begin{array}{c}15-03-08 \text { a } \\
22-03-08\end{array}$ \\
\hline $\mathrm{T} 4$ & 23-01-08 & $\begin{array}{c}02-04-08 \text { a } \\
09-04-08\end{array}$ & & $\begin{array}{c}02-04-08 \text { a } \\
09-04-08\end{array}$ & & $\begin{array}{c}09-04-08 \text { a } \\
16-04-08\end{array}$ \\
\hline
\end{tabular}

(*) TEST 1 = poda de inverno em 20-07-07, sem poda verde; TEST 2 = poda de inverno em 22-08-07, sem poda verde; T1 = poda de inverno em 20-07-07 e poda verde em 15-11-07; T2 = poda de inverno em 20-07-07 e poda verde em 17-12-07; T3 = poda de inverno em 22-08-07 e poda verde em 15-11-07; T4 = poda de inverno em 22-08-07 e poda verde em 17-12-07. 
TABELA 4 - Cotação de preços para a categoria uva comum de mesa. Fonte: CEASA. Porto Alegre-RS, $2007 / 2008$.

\begin{tabular}{cc}
\hline \multirow{2}{*}{ Data } & Uva comum de mesa \\
\cline { 2 - 2 } Preço/Kg (R\$) \\
\hline $27-12-2007$ & 2,14 \\
$30-12-2007$ & 2,00 \\
$03-01-2008$ & 2,00 \\
$06-01-2008$ & 1,67 \\
$10-01-2008$ & 1,67 \\
$16-01-2008$ & 1,50 \\
$19-01-2008$ & 1,33 \\
$23-01-2008$ & 1,17 \\
$30-01-2008$ & 1,00 \\
$08-03-2008$ & 1,71 \\
$15-03-2008$ & 1,71 \\
$22-03-2008$ & 1,86 \\
$02-04-2008$ & 2,29 \\
$09-04-2008$ & 2,29 \\
$16-04-2008$ & 3,57 \\
\hline
\end{tabular}

TABELA 5 - Produção média por planta na primeira e segunda na colheita das cvs. Niagara Branca (NB), Niagara Rosada (NR) e Concord. Eldorado do Sul-RS, 2007/2008.

\begin{tabular}{ccccccc}
\hline \multirow{2}{*}{ Cultivar } & \multicolumn{5}{c}{ Produção média $\left(\mathrm{kg} \mathrm{planta}^{-1}\right)$ primeira safra } \\
\cline { 2 - 7 } & Testemunha $1^{1}$ & Testemunha 2 & $\mathrm{~T} 1$ & $\mathrm{~T} 2$ & $\mathrm{~T} 3$ & $\mathrm{~T} 4$ \\
\hline NB & $11,54 \mathrm{aA}^{2}$ & $12,03 \mathrm{aA}$ & $11,06 \mathrm{aA}$ & $11,78 \mathrm{aA}$ & $10,15 \mathrm{aA}$ & $11,03 \mathrm{aA}$ \\
NR & $10,31 \mathrm{aA}$ & $11,02 \mathrm{aA}$ & $10,58 \mathrm{aA}$ & $10,95 \mathrm{aA}$ & $10,17 \mathrm{aA}$ & $10,72 \mathrm{aA}$ \\
Concord & $7,56 \mathrm{aB}$ & $8,05 \mathrm{aB}$ & $8,17 \mathrm{aB}$ & $8,34 \mathrm{aB}$ & $7,71 \mathrm{aB}$ & $7,94 \mathrm{aB}$ \\
\hline CV $(\%)$ & \multicolumn{7}{c}{23,98} \\
\hline \multirow{2}{*}{ Cultivar } & \multicolumn{7}{c}{ Produção média $\left(\mathrm{kg} \mathrm{planta}^{-1}\right)$ segunda safra } \\
\cline { 2 - 6 } & Testemunha $1^{1}$ & Testemunha 2 & $\mathrm{T} 1$ & $\mathrm{~T} 2$ & $\mathrm{~T} 3$ & $\mathrm{~T} 4$ \\
NB & --- & --- & $0,31 \mathrm{bA}{ }^{2}$ & $0,28 \mathrm{bA}$ & $1,26 \mathrm{aA}$ & $0,34 \mathrm{bA}$ \\
Concord & --- & --- & $0,21 \mathrm{bA}$ & $0,25 \mathrm{bA}$ & $0,84 \mathrm{aB}$ & $0,24 \mathrm{bA}$ \\
\hline CV $(\%)$ & --- & $0,16 \mathrm{bA}$ & $0,18 \mathrm{bA}$ & $0,48 \mathrm{aC}$ & $0,19 \mathrm{bA}$ \\
\hline
\end{tabular}

( $\left.{ }^{1}\right)$ Testemunha 1 = poda de inverno em 20-07-07, sem poda verde; Testemunha 2 = poda de inverno em 22-08-07, sem poda verde; T1 = poda de inverno em 20-07-07 e poda verde em 15-11-07; T2 = poda de inverno em 20-07-07 e poda verde em 17-12-07; T3 = poda de inverno em 22-08-07 e poda verde em 15-11-07; T4 = poda de inverno em 22-08-07 e poda verde em 17-12-07. $\left({ }^{2}\right)$ Médias seguidas pela mesma letra, minúscula na linha e maiúscula na coluna, não diferem significativamente, pelo teste de Duncan, a $5 \%$ de probabilidade.

TABELA 6 - Características químicas da primeira e segunda safras das cultivares Niagara Branca (NB), Niagara Rosada (NR) e Concord. Eldorado do Sul-RS.

\begin{tabular}{ccccc}
\hline \multirow{2}{*}{ Cultivar } & \multicolumn{2}{c}{ SST $\left({ }^{\circ}\right.$ Brix $)$} & \multicolumn{2}{c}{ ATT $\left(\mathrm{cmol} \mathrm{L}^{-1}\right)$} \\
\cline { 2 - 5 } & $1^{\mathrm{a}}$ safra & $2^{\mathrm{a}}$ safra & $1^{\mathrm{a}}$ safra & $2^{\mathrm{a}}$ safra \\
\hline NB & $15,17 \mathrm{aA}$ & $14,35 \mathrm{bA}$ & $6,62 \mathrm{bB}$ & $7,56 \mathrm{aB}$ \\
NR & $15,02 \mathrm{aAB}$ & $14,27 \mathrm{bA}$ & $6,87 \mathrm{bB}$ & $7,75 \mathrm{aB}$ \\
Concord & $14,63 \mathrm{aB}$ & $13,75 \mathrm{bB}$ & $7,84 \mathrm{bA}$ & $8,50 \mathrm{aA}$ \\
\hline CV $(\%)$ & \multicolumn{2}{c}{9,21} & \multicolumn{2}{c}{11,58} \\
\hline
\end{tabular}

Médias seguidas pela mesma letra, minúscula na linha e maiúscula na coluna, não diferem significativamente, pelo teste de Duncan, a $5 \%$ de probabilidade 


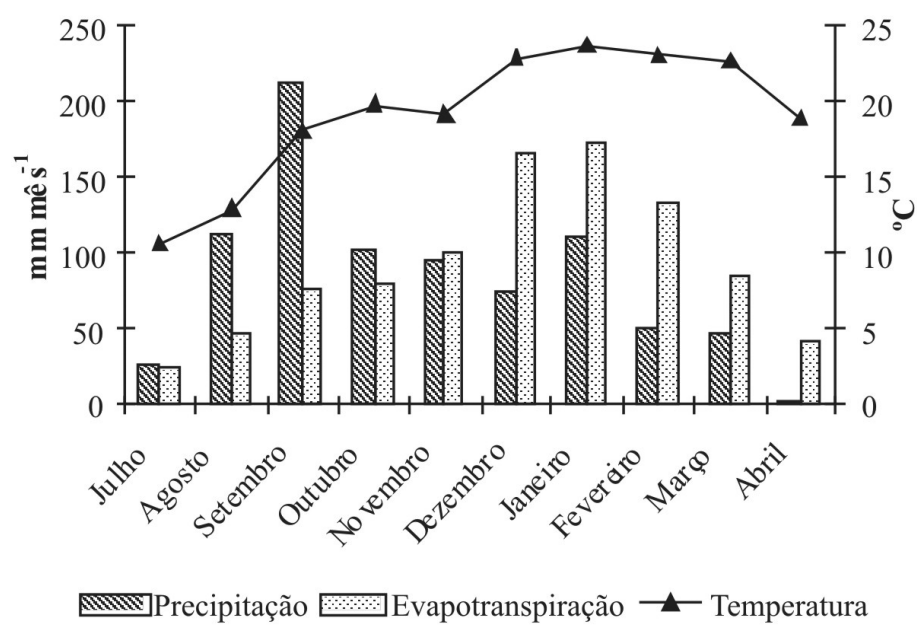

FIGURA 1 - Temperatura média do ar $\left({ }^{\circ} \mathrm{C}\right)$, precipitação pluvial $\left(\mathrm{mm} \mathrm{mês}^{-1}\right)$ e evapotranspiração de referência (mm mês ${ }^{-1}$ ) de julho de 2007 a abril de 2008, observados em estação meteorológica automática. Eldorado do Sul-RS.

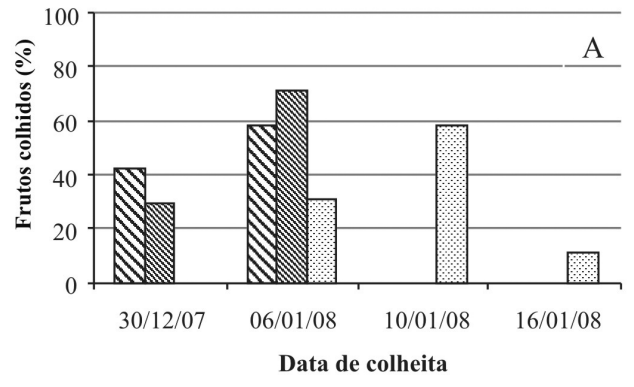

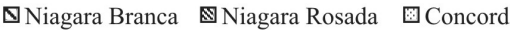

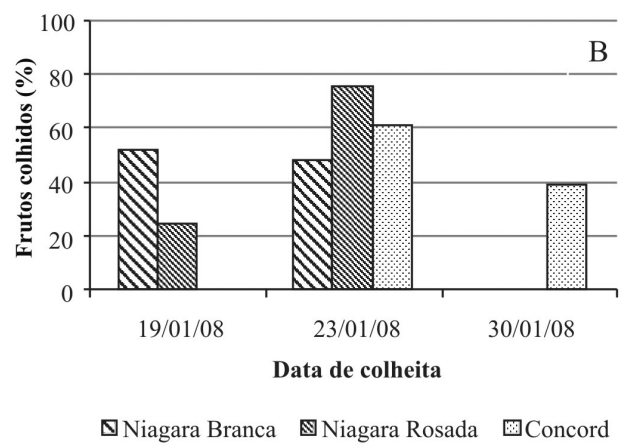

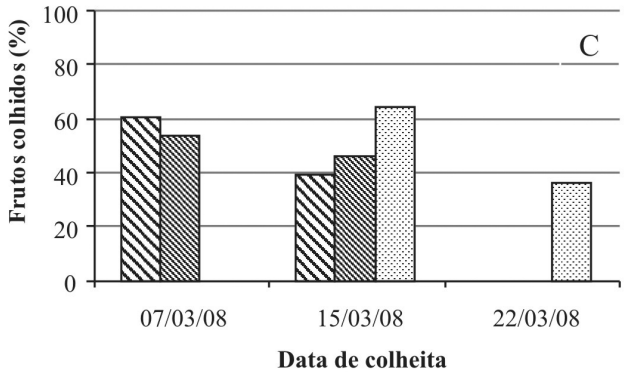

\$Niagara Branca $\$$ Niagara Rosada $\quad$ Concord

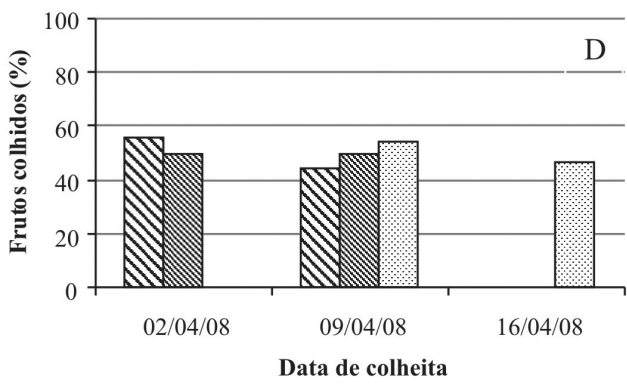

QNiagara Branca $\mathbf{s}$ Niagara Rosada $\quad$ r Concord

FIGURA 2 - Quantidade relativa de uvas colhidas na primeira safra (A e B) e segunda safra (C e D) das cvs. Niagara Branca, Niagara Rosada e Concord. Produção da primeira safra obtida pela poda de inverno em 20-07-07 (A) (Tratamentos T1* e T2*) e em (22-08-07) (B) (Tratamentos T3* e T4*). Produção da segunda safra obtida pela poda verde em 15-11-07 (A) (Tratamentos T1* e T3*) e em (17-12-07) (B) (Tratamentos T2* e T4*). Eldorado do Sul-RS. (*) T1 = poda de inverno em 20/07/07 e poda verde em 15-11-07; T2 = poda de inverno em 20-07-07 e poda verde em 17-12-07; T3 = poda de inverno em 22-08-07 e poda verde em 15-11-07; T4 = poda de inverno em 22-08-07 e poda verde em 17-12-07. 


\section{CONCLUSÕES}

1- A duração do ciclo produtivo de videiras 'Niagara branca', Niagara Rosada' e 'Concord', tanto na primeira como na segunda safra, varia de acordo com a cultivar e está diretamente relacionada à exigência térmica do genótipo e das condições climáticas do local de cultivo.

2-A antecipação da poda de inverno permite antecipar a colheita da primeira safra.

3-A poda verde retarda a colheita normal das cultivares Niagara Branca, Niagara Rosada e Concord, e propicia uma segunda colheita no período de entressafra na Depressão Central do Rio Grande do Sul, sendo a maior produção da segunda safra obtida quando a poda seca é realizada em agosto, e a poda verde, em novembro.

4-A utilização da dupla poda aumenta a produção total anual de uva, oferecendo vantagens econômicas ao viticultor e ampliando a disponibilidade da fruta ao consumidor.

\section{REFERÊNCIAS}

ANZANELLO, R.; GONZATTO, M.P.; SOUZA, P.V.D.de. Produção de videiras 'Niagara Branca' e 'Concord' submetidas a duas safras por ciclo vegetativo na Depressão Central do Rio Grande do Sul. Scientia Agraria, Curitiba, v. 9, n. 3, p. 311-316, 2008.

BERGAMASCHI, H.; GUADAGNIN, M.R.; CARDOSO, L.S.; SILVA, M.I.G.da. Clima da Estação Experimental da UFRGS (e região de abrangência). Porto Alegre: UFRGS, 2003. 78p.

CALEGARO, J. M.; PEZZI, E. ; BENDER, R. J. Utilização de atmosfera modificada na conservação de morangos em pós-colheita. Pesquisa Agropecuária Brasileira, Brasília, v. 37, n. 8, p. 1.049-1.055, 2002.

CAMARGO, U.A.; DIAS, M.F. Identificação varietal de algumas videiras cultivadas no Rio Grande do Sul. Bento Gonçalves: CNPUV- Embrapa, 1984. $47 \mathrm{p}$.

CEASA. Cotação de preços da uva comum de mesa no ano de 2007/2008. Disponível em: http:// www.ceasa.rs.gov.br/cotacao.htm. Acesso em: 21 set. 2008 .
CONTE, A. Comportamento da videira Niagara Rosada submetida à poda de verão, sob estufa plástica, em Bento Gonçalves - RS. 1996. 71f. Dissertação (Mestrado em Fitotecnia)- Faculdade de Agronomia, Universidade Federal do Rio Grande do Sul, Porto Alegre, 1996.

EUROPEAN AND MEDITERRANEAN PLANT PROTECTION ORGANIZATION. EPPO Crop growth stage keys: grapevines. EPPO / OEPP. Bulletin, Paris, v. 14, n. 2, p. 295-298, 1984.

FERREIRA, E.A.; REGINA, M.A.; CHALFUN, N.N.J.; ANTUNES, L.E.C. Antecipação de safra para videira Niágara Rosada na região Sul do Estado de Minas Gerais. Ciência e Agrotecnologia, Lavras, v.28, n.6, p. 1221-1227, 2004.

FOCHESATO, M.L.; SOUZA, P.V.D.de.; AGOSTINI, S. Obtenção de duas safras por ciclo vegetativo pelo manejo da poda. Revista Agropecuária Catarinense, Florianópolis, v. 20, n. 1, p. 53-57, 2007.

GHILARDI, A. A.; MAIA, M. L. Tecnologia, custo de produção e rentabilidade do cultivo de uva Niagara no Estado de São Paulo. Informações Econômicas, São Paulo, v.31, n.12, p. 48-64, 2001.

GIOVANINNI, E. Produção de uvas para vinhos, suco e mesa. 3.ed. Porto Alegre: Editora Renascença, 2008. 364p.

GUERRA, C.C.; DAUD, C.E.; RIZZON, L.A. Evolução dos ácidos tartárico e málico durante a maturação de uvas tintas. Pesquisa Agropecuária Brasileira, Brasília, v. 27, n. 3, p. 479-491, 1992.

JUBILEU, B. S.; SATO, A. J.; ROBERTO, S. R. Caracterização fenológica e produtiva das videiras 'Cabernet Sauvignon' e 'Alicante' (Vitis vinifera L.) produzidas fora de época, no norte do Paraná. Revista Brasileira de Fruticultura, Jaboticabal, v.32, n.2, p.451-462, 2010.

LEÃO, P.C.S.de; SILVA, E.E.G. Caracterização fenológica e requerimentos térmicos de variedades de uvas sem sementes no Vale do São Francisco. Revista Brasileira de Fruticultura, Jaboticabal, v. 25, n. 3, p. 379-382, 2003.

MANDELLI, F.; BERLATTO, M.A.; TONIETTO, J.; BERGAMASCHI, H. Fenologia da videira na Serra Gaúcha. Pesquisa Agropecuária Gaúcha, Porto Alegre, v. 9, n. 1-2, p. 129-144, 2003. 
MURAKAMI, K. R. N.; CARVALHO, A.J.C.de; CEREJA, B.S.; BARROS, J.C.S.M.; MARINHO, C.S. Caracterização Fenológica da Videira cv.Itália (Vitis vinifera L.) sob Diferentes Épocas de Poda na região norte do Estado do Rio de Janeiro. Revista Brasileira de Fruticultura, Jaboticabal, v. 24, n. 3, p. 615-617, 2002.

NEIS, S.; SANTOS, S.C.; ASSIS, K.C.; MARIANO, Z.F. Caracterização fenológica e requerimento térmico para a videira Niagara Rosada em diferentes épocas de poda no sudoeste Goiano. Revista Brasileira de Fruticultura, Jaboticabal, v.32, n.3, p.931-937, 2010.

POMMER, C.V.; TERRA, M.M.; PIRES, E.J.P. Cultivares, melhoramento e fisiologia. In: POMMER, C.V. Uva: tecnologia de produção, pós-colheita, mercado. Porto Alegre: Cinco Continentes, 2003. p. 109-152.

SANTOS, C.E.dos; ROBERTO, S.R.; SATO, A.J.; JUBILEU, B.S. Caracterização da fenologia e da demanda térmica das videiras 'Cabernet Sauvignon' e 'Tannat' para a região norte do Paraná. Acta Scientiarum Agronomy, Maringá, v. 29, n. 3, p. 361-366, 2007.

SATO, A.J.; JUBILEU, B.S.; SANTOS, C.E.dos; BERTOLUCCI, R.; SANTOS, R.dos; CARIELO, M.; GUIRAUD, M.C.; FONSECA, I.C.B.; ROBERTO, S.R. Fenologia e demanda térmica das videiras Isabel e Rubea sobre diferentes porta-enxertos na região norte do Paraná. Semina: Ciências Agrárias, Londrina, v. 29, n. 2, p. 283-292, 2008.
SOUZA, A. P.; SILVA, A. C.; LEONEL, S.; ESCOBEDO, J. F. Temperaturas basais e soma térmica para a figueira podada em diferentes épocas. Revista Brasileira de Fruticultura, Jaboticabal, v.31, n.2, p.314-322, 2009.

SOUZA, P.V.D.de; FOCHESATO, M.L. Emprego da poda verde para obtenção de duas safras por ciclo vegetativo em 'Niagara Branca'. Bragantia, Campinas, v. 66, n. 4, p. 527-533, 2007.

SOZIM, M.; FERREIRA, F. P.; AYUB, R. A.; BOTELHO, R. V. Época de poda e quebra de dormência em videiras cv. Niagara Rosada. Semina: Ciências Agrárias, Londrina, v. 28, n. 2, p. 201-206, 2007.

TECCHIO, F. M.; MIELE, A.; RIZZON, L. A. Composição físico-química do vinho Bordô de Flores da Cunha-RS, elaborado com uvas maturadas em condições de baixa precipitação. Ciência Rural, Santa Maria, v.37, n.5, p.1.480-1.483, 2007.

VILLA NOVA, N. A.; PEDRO JÚNIOR, M. J.; PEREIRA, A. R.; OMETTO, J. C. Estimativa de grausdia acumulados acima de qualquer temperatura-base em função das temperaturas máxima e mínima. Ciência da Terra, São Paulo, n.30, p.1-8, 1972. 